Madrygal. Revista de Estudios Gallegos

ISSN: 1138-9664

http://dx.doi.org/10.5209/MADR.62620

\title{
Un achado casual: un relato de María Victoria Moreno
}

Manuel Pereira Valcárcel

A primeiros dos anos 80 chegou ás miñas mans o libro Jogos Florais Minho-Galaicos 1970 . guimarães · 1971, publicado por Convívio, Associação Cultural e Recreativa, e que supón a edición dos traballos premiados en dito certame.

O tal libro, recibino de mans de María Jesús Rico Quiñones con quen eu acababa de casar e que traballaba no Ministerio de Educación y Ciencia, no departamento de provisión de prazas de Bacharelato. Naqueles anos aínda non estaban transferidas as competencias edu-

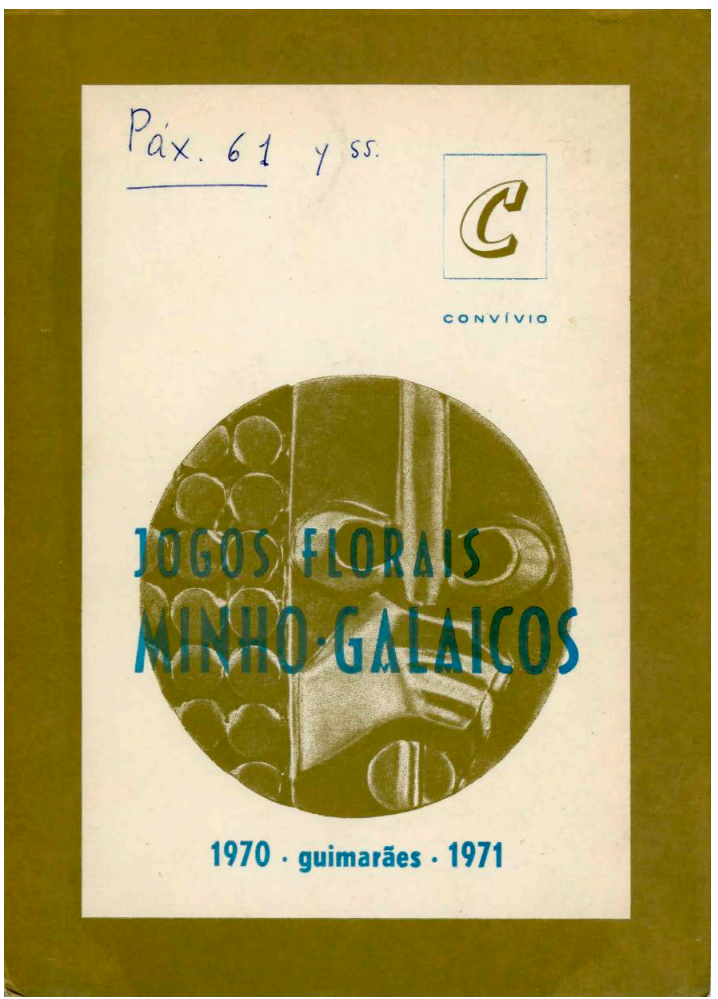

Portada do libro cativas ás comunidades autónomas e os concursos de traslados estaban organizados polo Ministerio. Todas as persoas que querían tomar parte nun destes concursos podían presentar as súas publicacións para que fosen baremadas e puntuadas como méritos.

Se os docentes non recollían os traballos presentados dentro do prazo establecido para a devolución, agardábase un tempo e despois pasaba a algún almacén e, pasado máis tempo, eran destruídos. María Jesús rescataba os traballos relacionados con Galicia e traíaos para a casa. Deste xeito, fíxenme con varios libros relacionados coa cultura galega da autoría de profesores de Ensino Medio que querían mudar de centro.

Entre estas publicacións está o citado volume cos textos dos Jogos Florais Minho-Galaicos. Entre eles un relato de María Victoria Moreno ("La casa de las Marías", pp. 6167) no que se desenvolve, en síntese, unha historia rural de paixóns, poder e vellos rancores; na que están implicados un crego e unhas prostitutas. A narración avanza cargada de descricións líricas e grandes elipses até o asasinato de dúas prostitutas e a conseguinte detención do autor pola Garda Civil na escena final.

Reproducimos o texto completo de María Victoria Moreno porque nel hai un pequeno parágrafo manuscrito a modo de xustificación, por parte da autora, do argumento e pasaxes do relato. A nota di así:

Quisiera hacer constar que las Fuerzas de orden público, al servicio de un gobierno justo, gozan de todo mi respeto. Asimismo el Clero, a condición de que no se apoye en privilegios políticos y practique, en nombre de Cristo, la solidaridad con los menos favorecidos. 
Como se pode entender, eran tempos onde cumpría medir as palabras, as intencións e o desenvolvemento dos personaxes, aínda que fosen obras de ficción. A restauración democrática era feble aínda. E esta narración incluía elementos e personaxes que esixían tacto para non ferir suspicacias, sobre todo se quen asinaba era unha funcionaria do ensino.

La Casa de las Marias

El cielo azul y el aire gris se mezclan en un halo de oro Polen, polvo y aromas maduros danzan sobre la tierra y bajo el cielo en ol atardecer veraniego. $\mathrm{Y}$ los vencejos, chirriantes aviones de acerados vuelos, están aturdidos, Su ir y venir rebota en el doblar de las campanas y parece envolver en sus múttiples vueltas al llanto que se levanta desde la tierra seca.

Dos mujeres vestidas de luto hablan en una esquina. E hombre que viene hacia ellas atrae su atención y se convierte e esperanza de saciar su sed. Sed de saber, que crece durante el día como las sombras, y es infinita en la puesta del sol.

El hombre saluda sin intención de detenerse y ellas le atajan :

Qué, señor Lorenzo, De las tierras?

-No. De la feria

Entonces no sabrá usted quién se ha muerio...

- No. Lo sabéis vosotras ?

Bueno, dicen que han matado a las Marías en el camin

de Fuentesanta al amanecer. Pero nadie sabe má

- Habrá sido para robarles.

Las mujeres se quedan en su esquina y con su duda. Lorenzo sigue, calle abajo, hacis su casa

$$
\begin{aligned}
& \text { La casa de las Marias } \\
& \text { es una casa de hembras; } \\
& \text { los hombres van por la noche }
\end{aligned}
$$$$
-61-
$$

Jogos Florais Minho-Galaicos, p. 61

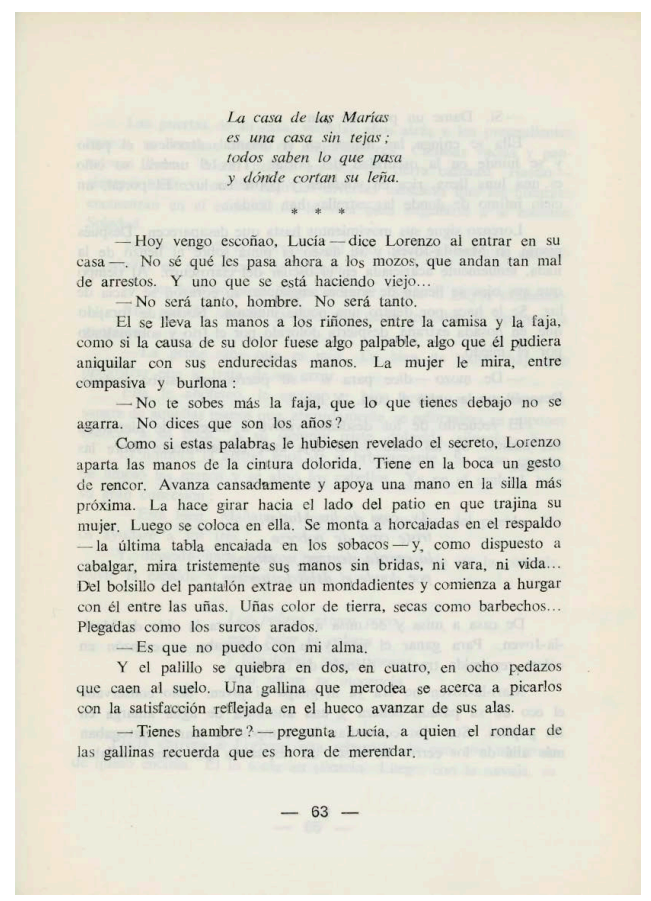

Jogos Florais Minho-Galaicos, p. 63
Velaquí, pois, o contido da narración de María Victoria Moreno tal como ela a presentou para ser valorada de cara a contabilizar os seus méritos e obter así a puntuación definitiva para o concurso de traslados. Como se pode ver na portada do libro, a autora sinalou á man as páxinas que corresponden ao seu texto que agora ofrecemos.

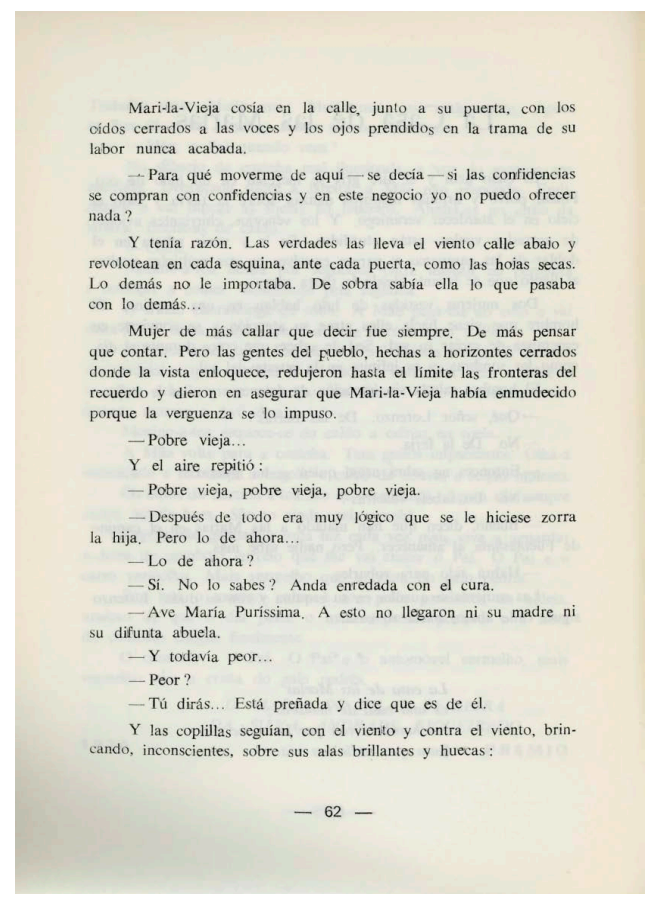

Jogos Florais Minho-Galaicos, p. 62

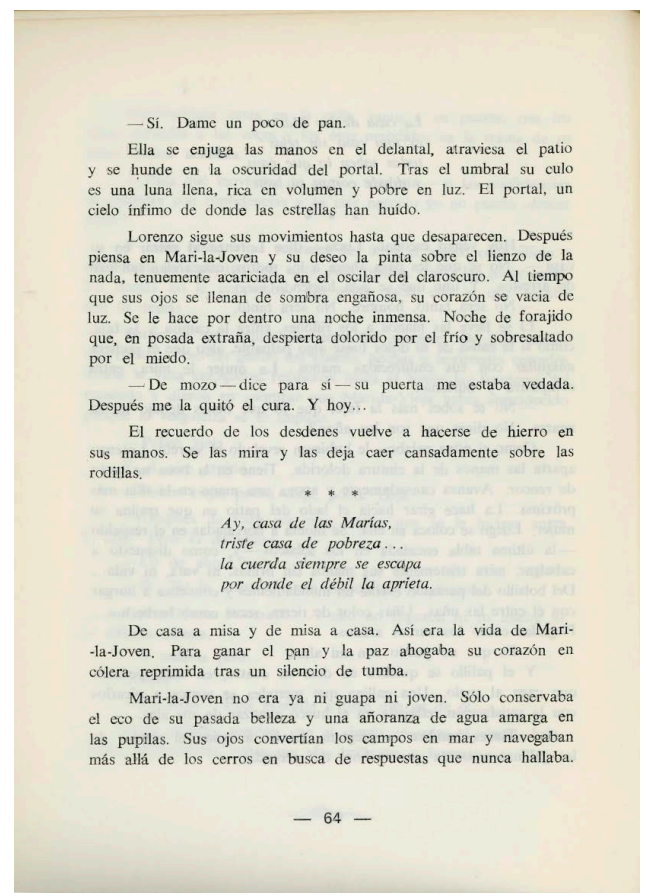

Jogos Florais Minho-Galaicos, p. 64 


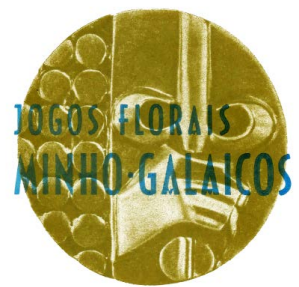

Las puertas de su casa, vedadas años atrás a los pretendientes mozos, se llenaban ahora de merodeadores. Camisas vacías y pantalones llenos. Metal helado en vez de tierra caliente. Hastioinpre hastio - aculto bajo las diversas máscaras que los hombre Soledad.

Incluso cuando la esperanza del hijo, cálida y luminosa, empezo a palpitar en su corazón, le dijeron

-Este hijo ne puede llegar a nacer. Sería el mayor escíndalo. Ella guardó silencio porque una garra invisible le op garganta. - La gente sabe que es mío. En bien de todos, hay que

scupió e hizo brotar a mordiscos la sangre de aquellas manos que, absurdamente, se esforzaban en imponer

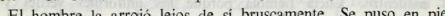
El hom la labellos. Ya en el umbral, hizo su gran concesión :

-Está bien. Mañana tu madre y tú os vais del pueblo. Yo

$\mathrm{Y}$, dejando unos.

pan Antonio de la cómoda, volvió la espalda y cerró la puerta.

$$
\begin{aligned}
& \text { Los pobres exigen poco } \\
& \text { para bajar la cabeza } \\
& \text { y los demás pagan meno } \\
& \text { para salvar su inocencia }
\end{aligned}
$$$$
\text { * * * }
$$

Lucia entrega a Lorenzo una rebangda de pan con un trozo de queso encima. El lo toma en silencio. Luego, con la navaja, va

$$
-65-
$$

Jogos Florais Minho-Galaicos, p. 65

cortando el queso sobre el pan y el pan sobre las refilexione -Quién las ha muerto, Lorenzo ? Tú lo sabes...

Bajo el pan tres gallinas se pierden el maíz del gallinero por disputarse las migajas. Lorenzo dice de cuando en cuando:

一 Qué pijas, coño. Qué pijas.

Y sigue comiendo pan sin sosiego y queso con pan.

Lucia continúa en su fregado.

-Quién las ha muerto, Lorenzo? Tú lo sabes...

El esquilón de la puerta la solicita. Se acerca a abrir sobresaltada, recordando el clamor de la campana y el aire taciturno que, sin saber por qué, se respira a su alrededor.

Es una pareja de la guardia civil. Lorenzo se levanta cansadamente $y$, en silencio, antes de que ellos abran la boca, les sale al encuentro. Lucia tiembla porque los uniformes verdes y los tricornios de charol van siempre sembrando congojas, aunque pasen de lejos. Mira a su marido con ojos interrogantes, como queriendo repetir una vez más :

-Quién las ha muerto, Lorenzo? Tú lo sabes.

El la besa en la mejilla, la mira, busca palabras en los escondrijos del alma... Las va encontrando poco a poco:

- Volveré pronto.

Lucia no entiende.

No ha sido por mi culpa. Se pusieron muy tercas. Luego a vieja queria gritar

Ella palidece.

Dile a los chicos la verdad: he matado a las Marias, pero yo no quería hacerlo, te lo juro. Sólo quería que se quedasen aquí.

La mujer llora desesperadamente.

$$
-66-
$$

Jogos Florais Minho-Galaicos, p. 66

- Las han engañado, Lucía. Tenian que quedarse aunque sólo fuese por amolar a quien tú sabes.

Lucía se limpia las lágrimas en a punta del delantal y Lorenzo, entre los guardias, emprende la cuesta arriba El doblarenzo, campanas y el murmurar de las esquinas le acompinar de la silencio.

MARIA VICTÓRIA MORENO MARQUEZ

1971

1. PREMIO

Quisiera hacer coustor que hes Inertas de orden publico. ol fervicio de un qubierno iusto, goton de toolo mi resneto. Asimismo el Clero, a coudicion de qu no re apoye en privilegios politicos y practique. en nombre de Cristo, la solidaridod con los unenos fovorecidos.

$$
-67-\frac{\text { Mavid V Moreus }}{1979}
$$

Jogos Florais Minho-Galaicos, p. 67

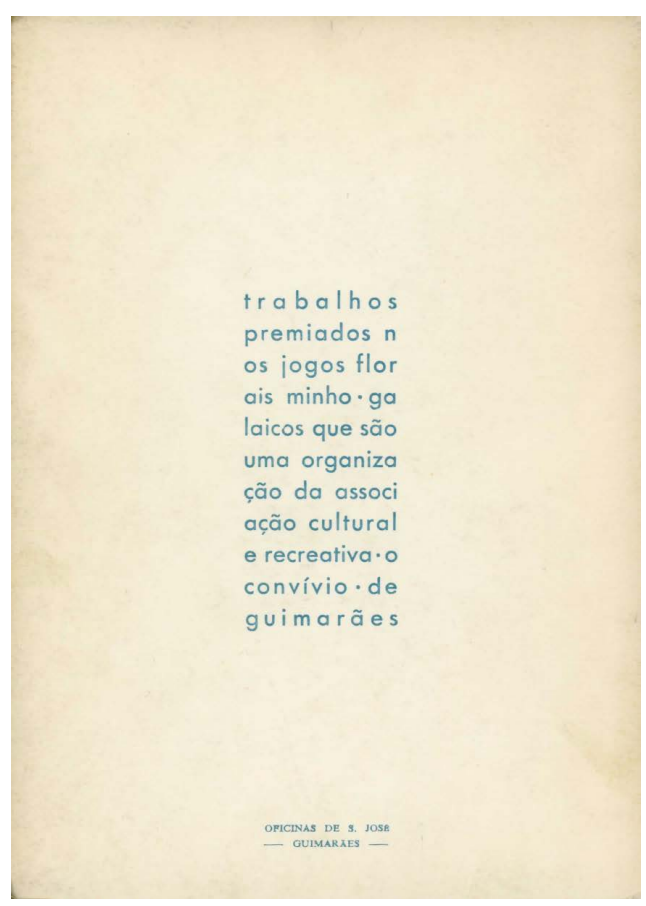

Contraportada do libro 